\title{
Modernising human resource management in times of financial crisis: What priorities to maintain capacity with limited resources?
}

\author{
Danielle Bossaert \\ European Institute of Public Administration, Maastricht, Netherlands \\ Email address: \\ d.bossaert@eipa.eu
}

To cite this article:

Danielle Bossaert. Modernising Human Resource Management in Times of Financial Crisis: What Priorities to Maintain Capacity with Limited Resources? Journal of Human Resource Management. Vol. 2, No. 1, 2014, pp. 9-15. doi: 10.11648/j.jhrm.20140201.12

\begin{abstract}
Currently and in the next few decades, national public services ${ }^{1}$ of the EU Member States will be confronted with a smaller and older workforce due to demographic change, downsizing, and restructuring. The effects of this trend are less capacity, risks of skill obsolescence, of lower performance and of productivity and know-how loss. In that context, HRM in the European public services needs to play a stronger role by using more effectively the skills and competencies of its current and future workforce. Against this background, the article discusses common European priorities in the fields of HR planning, career management, skills development and training, which are needed to also maintain in future a competent and high quality public service.
\end{abstract}

Keywords: Financial Crisis, More Limited Resources, Human Resource Management, Development of Skills and Competencies

\section{Introduction}

It is not only the private sector, but it is also the public sector, which has been deeply hit by the financial crisis. Effects of this crisis are cuts in operational expenditures such as workforce reductions, cuts of salaries and benefits in many public services of the OECD countries. France for instance, decreased its operational costs by $10 \%$. In the Netherlands, these savings amount to EUR 6 billion by $2015^{2}$. In the same way, in the UK, the operational expenditures will be reduced by between $33 \%$ and $42 \%$ by $2014 .^{3}$ There exists a general trend to reduce staff and to decrease personnel costs. In Estonia, personnel costs are decreased by $15 \%$, in the Czech Republic staff is reduced by $10 \%$ in 2010 , while the UK planned a reduction of 490 000 jobs and the Netherlands a reduction of 120000 to 150 000 jobs. $^{4}$ The size of the future workforce in the EU Member States is further on reduced by a lower number of recruitments. Austria and France for instance plan to only replace $50 \%$ of retiring staff, while Italy only wants to replace $20 \%$ of its retirements and Spain $10 \% .^{5}$

In view of a high probability of more moderate economic growth rates in the next years, it is to be expected that the spending priorities of governments for state personnel will not change dramatically in the next future. ${ }^{6}$ According to a projection of the European Commission, growth will also remain moderate during the next decade: they predict for the EU as a whole that after an average potential growth of $1,5 \%$ up to 2020 , a slight increase to $1,6 \%$ is projected in the period 2021-30. ${ }^{7}$

Due to demographic change and its effects of a smaller active population and a higher retirement age, it is also not to be expected that the number of recruitments will go up substantially. These developments will however lead to a higher average age of the workforce: According to statistics, overall in the EU 27, the participation rate of older people (55-64) is estimated to increase by about 8,3\% in 2020 and even by $14,8 \%$ in 2060 as an effect of the projected impact of the pension reforms. ${ }^{8}$

Thus, in the next decade, the management of human resources will take place in a different financial, social and economic context. In such a changing environment being characterised by fewer and older staff, more moderate budgets and continuing technological and societal change, HRM should focus much more on tools and instruments, which promote a more strategic, forward-looking and competency-based approach. The strength of such an approach is that it promotes a better and more efficient planning of scarce resources as well as a more effective use 
of people's skills and competencies.

\section{Future Trends of Public Employment in the National Public Services of the EU Member States}

\subsection{The Development towards a Smaller and Ageing Workforce}

Particularly since the financial crisis of 2008, most of the national public services of EU Member States have to cope with a fairly new challenge: while general Government expenditure went up until the mid-eighties, this trend has slowly changed since then and definitively came to an end during the financial crisis. ${ }^{9}$ Since then, we can observe a contraction trend, which is characterized by developments such as restructuring, downsizing, recruitment freezes and replacement ratios. ${ }^{10}$ According to the OECD, three quarters of their member countries plan or already have introduced reforms, which decrease the current size of their workforce in more than half of the agencies and ministries of central government. ${ }^{11}$

Research shows that the pressure to review the size and expenditures of public organisations is highest in those public sectors, in which the budgetary debt is highest such as in Portugal, Spain and Ireland and less acute in Sweden and Germany, which already had reformed their public sector in the $80 \mathrm{~s}^{12}$

Moreover, the high number of recruitments in most of the national public services in the 70 s will lead in the coming years to a massive wave of retirements due to the baby boom generation reaching their pension age. In 13 OECD countries, over $30 \%$ of public employees of central government will leave during the next 15 years. ${ }^{13}$

Due to demographic change, the future workforce will be much older. The average age of staff will shift it is estimated that in the German civil service, the over 55 years old rose by nearly $6 \%$ in 2000 from $15,3 \%$ to $21,5 \%$ in 2009. This figure varies across Europe: While the percentage of central government employees aged $50+$ is very high in Italy $(49,2 \%)$ and Iceland $(45,5 \%)$, it is a bit lower in the French civil service (32\%). ${ }^{14}$

OECD statistics show that ageing in the central government workforce will also continuing in most of the European countries.

\subsection{Description of the Challenges Ahead}

What are the effects of this substantial change of the composition of the public sector workforce? In how far is the quality of our public services at risk due to fewer and ageing resources and how to react?

The findings of research are not explicit in this regard. As Demmke ${ }^{15}$ observes, it can be distinguished between three groups of experts. While the first group of experts ${ }^{16}$ evaluates that the current public sector workforce will face very serious challenges, which will threaten the public welfare state, the second group of EUPAN experts under the Danish Presidency in 2012 came to the conclusion that the crisis would bear opportunities to improve the efficiency and effectiveness of public administrations and that policy makers would seek efficiency through new approaches to work organisation. Lastly experts from the OECD are afraid that the focus will shift towards managing staff only as a cost factor rather than as an asset in which it is worthwhile to invest for superior performance and motivation.

The author of this article shares the view that the crisis will have to lead to new approaches to work and HR practices, while identifying as a major risk that staff will in future be merely seen as a cost factor and not as an asset. One of the biggest challenges, which HRM will face in the future, is to make a more effective use of the skills and competencies of a more limited workforce. In this field, professional and highly skilled HRM departments definitively need to play a more important role.

How to better use staff's competencies? Firstly by investing more in the productivity and performance of an ageing workforce, upon whom most of the future service delivery will depend. Key areas of action include the combat of the deficit model of the 70s, according to which work productivity peaks in the 30s and 40s and decreases afterwards and of negative stereotypes about employees above 50 .

Recent research ${ }^{17}$ has come to more positive results about the potential productivity and performance of older workers. It demonstrates in a comprehensive way that the link age decline of skills, productivity and knowledge is much less clear and more complex than firstly thought. ${ }^{18}$ Much depends upon how people are using their skills during their lifetime and the fact that they are using them very differently leads to a high variability in work productivity within age groups. In short, adults who continuously use their skills will continue to develop their potential, while those who don't, risk losing them. According to this theory, skills are like muscles that need continuous development and 'intellectual' challenges. ${ }^{19}$

Recent research ${ }^{20}$ also shows that an ageing workforce doesn't necessarily perform less well than a younger workforce. There is however evidence that a decline of skills and performance strongly correlates with insufficient training and development or also with work structures that are detrimental to competence development and are lacking learning incentives as also recognition, valorisation and motivating feedback.

Care is further on to be taken that public employees don't face risks of skill obsolescence or the lack of up-to-date knowledge and skills necessary to maintain effective performance (CEDEFOP). Skill obsolescence happens in case of insufficient training and is at the origin of skill gaps and can lead consecutively to lower productivity and innovation - which are future key competencies needed. Older employees do more often than their younger colleagues face the risk of out-dated 
knowledge or of a depreciation of working methods. ${ }^{21}$ Due to the rapidity of technological and economic change, the risk of skill obsolescence is increasing in the private and in the public sector.

Secondly, the existence of lesser and older staff requires a more targeted workforce planning and allocation of personnel, professional and modern $\mathrm{HR}$ offices being characterized by a high level of expertise in the fields of career management as well as a better linkage of HRM to strategic organizational goals and objectives.

In times of scarce resources and skill shortages, much more depends upon the capacities of public organisations to well plan their recruitments and to make sure that the right skills are in the right place and that they support the achievement of the organisational strategy.

Thirdly, a major obstacle of a more effective use of limited organisational competencies is skill mismatch. ${ }^{22}$ It is thus estimated that around $30 \%$ of the working population in Europe is affected by over education, while this same figure is believed to be even higher for under education. $^{23}$ Recent research ${ }^{24}$ illustrates the negative effects of skill mismatch on productivity: studies show that undereducated employees are less productive as compared to matched colleagues within the same job, while they have presumably less incentives to engage in skills improvement. Over education is also often linked to higher absenteeism, quits, turnover rates and shirking, although there is no clear link between over education and lower productivity.

\section{What Priorities to Make the Best Use of Limited Human Resources?}

\subsection{Human Resource Management Approaches Facilitating a Strategic and more Effective Workforce Planning}

As compared to the private sector, workforce planning in the public sector is much less advanced and it remains according to the OECD 'a rather weak point ${ }^{, 25}$ during the restructuring processes. This 'weakness' became in certain countries such as Ireland apparent during the financial crisis, because important information related to strategic HR needs was lacking and making more difficult policy choices about organizational adjustments measures. ${ }^{26}$

Among the major reasons for this rather low prioritisation of workforce planning are the political context with the short-term political decision-making approach, which renders the introduction of a thorough strategic management more difficult than in the private sector. Other more specific obstacles include the lack of important, strategic HR tools such as an overall organisational vision and mission, which often lead to fragmented and insufficient workforce planning.

Along these lines, replacements are hardly planned in advance, while there often exists no profiles or selection requirements for high executives. In times of tight labour markets and massive retirements, much more care should be given to succession planning and in general to effective forward planning instruments and to a better consideration of future competency needs and challenges.

France has introduced a good example of an effective forward planning workforce instrument in the public sector. Its objective is to prevent skill gaps in an environment of rapid economic, technological and demographic change and to align personnel with organizational goals.

\subsubsection{The Forward Workforce Planning Approach of the French Central Public Administration ('La Gestion Prévisionnelle Des Emplois Et Des Compétences' $)^{27}$}

In the early 1990's and revised in 2001, the French government introduced a new HRM planning instrument, which aims to maintain HR and organizational capacities in a smaller and greyer public sector. The Government set-up an ambitious unit in the Ministry of Civil Service, which is charged to analyse on a regular basis the public sector employment situation in view of forecasting personnel needs. Its objective is to make sure that the pool of existing staff and competencies in the civil service matches the needs of future demands and that skill shortages, which put at risk economic growth, are prevented.

One of the main tasks of the government-wide unit is to support ministries in their efforts to set up their forward planning HRM approach in alignment with the state budget and organisational missions.

The tasks of the GPEEC are a regular follow-up of numbers, of competencies of posts and of careers. Of particular importance are the anticipation of retirements and the definition of needs of recruitments while taking into account the governmental missions and growth objectives. The objective of GPEEC is also to be more proactive to the changing demands in civil services by an ageing population and to anticipate the changing policy priorities and needs of internal re-structuring.

A strong point of the GPEEC is that it is not a stand-alone activity, but that it is embedded in a generally more strategic management approach introduced by the LOLF $^{28}$, which stronger links organisational goals and workforce planning to budgetary priorities.

The introduction of the GPEEC in the French civil service shows that strategic workforce planning is a much more complex and long-term process in the public sector than in the private sector. This can partly be explained by the fact that in the case of the public sector, we have to deal with much larger organisations being characterized by different administrative levels and multiple layers of decision-making and which often employ millions of staff in different functions and grades.

As already mentioned earlier, striking trends of most of the European public services are their ageing workforce and a growing number of retirements also in the future. These developments require the introduction of HR tools, which increase the organisational awareness for age imbalances, developments of age curves, retirements, recruitment needs etc. Such instruments can for instance 
also be used for succession planning of leaders and of other positions.

In view of maintaining organisational capacity, Germany has introduced in 2012 in the context of its age conscious HRM an HR tool, called 'age structure analysis': its objective is to support the different ministerial departments in their efforts to analyse the age structure of different employment groups and different sectors and how they are developing. ${ }^{29}$

\subsubsection{The Age Structure Analysis as a Major Pillar of a More Age Sensitive Human Resource Management in the German Central Public Administration ${ }^{30}$}

The German Ministry of the Interior has only introduced the Altersstrukturanalyse very recently in 2012 to support its new HR concept 'Demography sensitive personnel management'. The Ministry of the Interior, which is responsible for the personnel policy of the federal government, supports ministries during the implementation of the new HR tools such as also the age structure analysis. For this sake, it has published guidelines and recommendations concerning the use of this instrument including the use of IT tools.

It comprises four steps:

1. Inventory of the current age structure of staff. Its aim is to create a picture of the current workforce and to identify strong imbalances regarding the age of staff.

2. Forecast of the future age structure (e.g. personnel fluctuations, recruitments, retirements). The analysis of the future age structure aims to forecast potential changes to the current age structure and to identify future challenges in the field of personnel policy. This analysis takes into account retirements, recruitments and other fluctuations.

3. Definition of a need based action plan and solutions. On the basis of step 1 and step 2 practice oriented activities and strategies are defined, which contribute to maintain also in future a productive and sustainable public administration. Areas covered include personnel recruitment and retention, qualification, personnel development, performance incentives, work organisation etc.

4. Involvement, communication and information. All stakeholders such as interest groups, the data protection officer and public employees are involved in the implementation process since the beginning.

It is still too early to evaluate the strengths and weaknesses of this HR tool. What can however already be said is that HR instruments such as the age structure analysis or also the GPEEC are good examples of a professionalization of workforce planning and in general of HRM in the public sector. They are important steps towards a more targeted recruitment and selection and important tools for a better alignment of HR with organisational priorities. It should however also be mentioned that the implementation of these 'new' HR tools in the public service requires strong HR departments being staffed by competent and motivated people as well as committed senior civil servants being characterized by good leadership and strategic skills.

\subsection{Human Resource Management Priorities to Enhance Skills Development and Productivity of an Ageing Workforce}

Current principles of career management in the public sector have been designed in different economic times being characterized by generous budgets, a higher number of recruitments (the 'baby boom generation') and a policy of early retirement. After a linear and vertical progression, careers often peak between 40-50 with limited opportunities for further development, job or task change, mobility, career progression and training. The participation of older workers in training courses is in most of the European public services rather low $^{31}$, which leads to risks of skill obsolescence and skill mismatch.

Recent HRM reform initiatives which aim to promote longer working lives in the context of demographic change, include the following: the introduction of new roles for seniors, of mid-career interviews aiming to discuss future career and skills development, of new forms of training and training methodologies and the promotion of a better use of age specific competencies in job tasks.

The added value of these measures is their encouragement of a more active management of seniors' skills and careers through job counselling and coaching, a better use of their experience through knowledge transfers and more tailor-made training activities, which better target the different needs of all age groups. Examples already implemented in the private sector are the creation of different learning methods for different age groups, the creation of career counsellors at company level ensuring a more individualized career guidance of seniors; the establishment of individual training plans, the introduction of support mechanisms for the development of (new) competencies and a stronger valorisation of the special know-how of an ageing workforce.

There is no evidence that older workers have lesser learning capacities than younger workers, it is only true to say that they learn in a different way. Training of seniors in the same way as training of adults should be linked to existing professional experience by referring to concrete work tasks, build on existing skills, be participatory and interactive, encourage a mixture of practice-oriented learning and working and take place at peer level. ${ }^{32}$

Training should moreover be interpreted in a broader way and include all different situations, where learning can occur. It can for example take place in front of the computer with an e-learning programme, as project leader during the implementation of a quality management tool, as participant in a European network or community of practice or also as a coach or mentor during working time or through knowledge sharing between juniors and seniors.

In public sectors characterized by massive retirements, the prevention of knowledge loss becomes crucial. Hence 
one effective methodology to maintain knowledge within the organisation is to transfer it from seniors to juniors. A good example of how older employees can be given a valorising and challenging new career role, during which they can use their know-how and experience to the benefit of the organization, is a tool used in more and more ministries of the public administration in Belgium.

\subsubsection{Knowledge Transfer between Senior-Juniors in the Belgian Civil Service ${ }^{33}$}

The Belgian Ministry of Civil Service has put in place in 2010 a user-friendly tool to transfer knowledge between seniors and juniors in a planned, structured and systematized way. Its aim is to safeguard important and scarce knowledge. It is particularly aimed at seniors, who hold key positions and are preparing for their retirement in a mid-term perspective. Three tools characterize the knowledge transfer: 1. A task map, which identifies crucial organisational knowledge, 2. The knowledge transfer plan and 3. The survival kit or the essentials of the transfer plan in writing. The last tool is especially important, if the junior is not yet in place before the senior leaves. Each of the three tools describes the role and tasks to be played by the three major actors: the senior, the junior and head of unit. The most crucial criteria for launching a knowledge transfer process is the identification of organizational fields of expertise as being of high relevance for the organization.

The tool distinguishes between four methods of knowledge transfer: 1. Learning through observation; 2. Learning through oral or written explanation; 3. Learning through simulation (mise en situation). The junior executes the task or part of it which the senior has accomplished so far; 4. Learning through analysis and through identification of successful strategies of solution-finding.

In a general way, knowledge sharing between seniors and juniors is also more successful than most technological solutions, because people use to learn best through face-to-face learning.

The practice of knowledge sharing between young and old shows however that the success of this tool is linked to certain cultural pre-conditions and is not always functioning very well. ${ }^{34}$ Some public organizations are simply apathy about sharing knowledge or they are characterized in general by a culture of transparent and insufficient communication. The most disturbing factor to an effective knowledge exchange is a competitive organizational culture which favours knowledge hoarding and where the possession of information is one of the most important power sources.

Practice shows that it is not always easy to implement knowledge management tools and that an important pre-condition is an environment which is characterized by a learning culture, procedural fairness, functioning ethical rules, and objectivity and correct and respectful interpersonal relationships.

Along these lines, the European guide to good practice in knowledge management distinguishes between knowledge aware cultures and cultures with a low awareness of knowledge. $^{35}$

Other examples of similar practices in the field of knowledge transfers are used in the French and German public administration. ${ }^{36}$

The enhancement of skill development and productivity of an ageing workforce depends on the one hand upon remedial measures and on the other hand upon a preventive approach, which guarantees appropriate learning, development and career opportunities during the whole career and at all ages. ${ }^{37}$

A good example in this context is the French law on mobility in the civil service, which has been adopted in $2009 .^{38}$ It favours longer and more flexible careers by abolishing important mobility obstacles such as different remuneration and allowance systems in different departments and it sets positive incentives through opening-up all corps and functions for secondment, the creation of a right for mobility for all public employees and the recognition and certification of prior professional experience.

Career paths, career flexibility, mobility, career progression and the organisation of end careers are key issues to maintain the expertise and motivation as well as the productivity of an ageing workforce. A comparative view of HR measures and tools discussed in different EU Member States illustrates similar trends and developments. Important topics discussed are the following ${ }^{39}$ :

- The creation of new job functions at end career (e.g. coach, consultant, tutor, mentor);

- The change from linear and vertical career paths to more zigzag careers favouring horizontal mobility and promoting more task flexibility;

- The establishment of more personalized career guidance and a better support of career management by introducing a mid-career appraisal to be regularly repeated by an expert in career guidance;

- The prolongation and diversification of professional careers by preventing public employees to reach the top of their career at the age of 50;

- The introduction of a more individualized HR and career management, which better takes into account individual skills and competencies;

- The development of age related training approaches;

- The promotion of a culture of intergenerational learning, team building and management;

- The change of rigid and detailed job descriptions to broader competency profiles being used organization-wide and which facilitate inter-organizational mobility.

The implementation of these HR measures requires on the one hand the need for a more competency-based career management or in other words a shift from purely seniority-based functions towards competency-based job profiles or professions being valid for the whole organisation. Such an HRM approach also encourages horizontal job mobility and professional development as 
well as longer careers and a better match between jobs and individual needs.4. Conclusions

The article has shown that the composition of the public sector workforce in the national public services will be changing during the next decade. This development will bring about new HRM challenges, to which national Governments should react in order to ensure enough capacity to maintain also in future a competent and performing public service.

Major challenges identified are a more limited number of human resources, which have to cope with the same workload and an ageing public service workforce, whose careers and professional development need to be managed in a different way than is the case today.

Priority strategies for an effective use of scarcer resources are a more effective workforce planning aligned to organisational goals and priorities as well as a more effective investment in skills of all ages and a more competency-based career management in general. What impacts negatively are that HR offices are very often staffed by generalists or by HR officers, who have no say in managerial decisions and are consequently not involved in important strategic decision-making processes nor in other relevant management issues.

As compared to the private sector, public service organisations often lack 'early warning mechanisms' or analytic tools, which are capable to anticipate future challenges and important internal and external developments such as in the context of demographic change and economic crisis.

The introduction of such tools requires the development of HR departments towards real strategic 'partners' of management, which are equipped with effective managerial and HR tools and skills.

Last but not least, fewer and ageing human resources require more flexible organisations with longer and more varied careers, opportunities for mobility, change of career tracks and task re-design.

\section{References}

[1] The public service includes all the public organisations which work under the authority of the political power and which serve the executive in the decision-making process.

[2] OECD, Public servants as partners for growth, Paris 2011, p.21.

[3] Ebd.,, p.21.

[4] Ebd., p.26

[5] Ebd., p.26

[6] According to the OECD, real GDP growth in the Euro area will be $1,3 \%$ in 2014 and $1,8 \%$ in 2015 . OECD, Economic Outlook NR 94, Paris 2013, p.3.

[7] European Commission, The 2012 Ageing Report, Economic and budgetary projections for the $27 \mathrm{EU}$ Member States
(2012-2060), Brussels 2012, p.75.

[8] Ebd., p.63.

[9] C. Pollitt and G. Bouckaert, Public Management Reform, Oxford: Oxford Press, 2011, p. 135ff.

[10] According to the OECD, 15 countries have realised replacement ratios with targets going up to $50 \%$ of staff being not replaced. OECD, Government at a glance, Paris 2011, p.108.

[11] Ibid., p.108.

[12] D. Vaughan-Whitehead, The impact of public sector adjustments in Europe, 28 June 2012, http://www.ilo.org/traveil/WCMS_184297/lang (last checked, 25.02.2013).

[13] OECD, Government at a glance, Paris 2009, p.72.

[14] OECD, 2011, op.cit. p.106.

[15] C. Demmke and T. Moilanen, The future of public employment in central public administration, study commissioned by the Chancellery of the Prime Minister of Poland, European Institute of Public Administration, Maastricht 2012, p.60ff.

[16] G. Symon and S. Corby, 'Making sense of public sector employment relations in a time of crisis', in S. Corby and G. Symon, Working for the state, Hampshire 2011, p.235.

[17] CEDEFOP, Working and ageing, Emerging theories and empirical perspectives, Luxembourg 2010, p.42ff.

[18] J. Behrens and F. Frerichs, 'Training, skills and performance of ageing workers - Issues, measures and models, in: $\mathrm{H}$. Buch and B. Dworschak, Ageing and work in Europe, Stuttgart 2003, pp.107-110; V. Skirbekk, 'Age and productivity capacity: descriptions, causes and policy options', Ageing Horizons, Nr 8, 2008, pp.4-10.

[19] R. Desjardins and A. Warnke, 'Ageing and skills: A review and analysis of skill gain and skill loss over the lifespan and over time', OECD Education Working Papers, No. 72, Paris, p. 13-14.

[20] V Skirbekk, 'Age and Productivity Capacity: Descriptions, causes and policy options', Ageing Horizons, Issue $\mathrm{Nr} 8$, p.4-12; P. Hendrik Van Dalen et al., 'Productivity of older workers perceptions of employers and employees', Population and Development Review 36(2) 2010, p. 309-330.

[21] CEDEFOP, Skill mismatch, Luxembourg 2012, p.15.

[22] Ibid., p.11.

[23] CEDEFOP, 2012, p.15.

[24] Ibid., p. 16.

[25] OECD, Ageing and the public service, Paris 2007, p. 35.

[26] Institute of Public Administration, 'Workforce planning in the Irish Public Service', Newsletter, Spring 2012, p. 1-4.

[27] For more details, see www.fonction-publique.gouv.fr

[28] Loi organique relative aux lois de finances. The LOLF is in the context of French public finances superior to the other financial laws and like a financial constitution. 
[29] See in this context: Bundesministerium des Innern, Demografiesensibles Personalmanagement in der Bundesverwaltung, Berlin 2012.

[30] See for more details www.verwaltung-innovativ.de

[31] D. Bossaert et al., 'The impact of demographic change and its challenges for the workforce in the European public sectors', EIPA Working Paper 2012/W/01, p.33.

[32] Ibid., p. 32ff.

[33] See for more details www.fedweb.belgium.be

[34] CEN/ISSS Knowledge Management Workshop, Europäischer Leitfaden zur erfolgreichen Praxis im Wissensmanagement, Brüssel, Frühjahr 2004, p.7.
[35] Ebd, p.8.

[36] Ministère de la Fonction publique, La transmission des savoirs, guide méthodologique, Paris 2007 ; Bundesministerium des Inneren, Demografiesensibles Personalmanagement in der Bundesverwaltung, Berlin 2012, p.10ff.

[37] Bossaert D., et al., 2012, p.18ff.

[38] Loi n²009-972 du 3 août 2009 relative à la mobilité et aux parcours professionnels dans la fonction publique.

[39] Ministère de la Fonction publique, Recueil de bonnes pratiques en matière de gestion des âges de la vie: Expériences des secteurs publics et privés en France et à l'international, Paris 2012. 